\title{
Analysis of Superconducting Fault Current Limiter in DC System with Renewable Energy Sources
}

\author{
S.Sanjeeva Rayudu, C.Ganesh, B.Vignesh Naik \\ Department of Electrical \& Electronics Engineering, Annamacharya Institute of Technology \& Science, India
}

\begin{tabular}{|c|c|}
\hline Article Info & ABSTRACT \\
\hline Article history: & $\begin{array}{l}\text { Superconducting fault-current limiters (SFCLs) have been the subject of } \\
\text { research and development for many years and offer an attractive solution to }\end{array}$ \\
\hline Received Jan 11, 2016 & the problem of rising fault levels in electrical distribution systems. SFCLs \\
\hline Revised Feb 16, 2017 & can greatly reduce fault currents and the damage at the point of fault, and \\
\hline Accepted Feb 21, 2017 & $\begin{array}{l}\text { help improve the stability of a power system. Superconducting fault-current } \\
\text { limiters (SFCL) provide a new efficient approach to the reliable handling of }\end{array}$ \\
\hline Keyword: & $\begin{array}{l}\text { and can be adapted to particular limiting characteristics in case of short } \\
\text { circuits. In this project, de resistive type superconducting fault current limiter }\end{array}$ \\
\hline DC system & (SFCL) is presented. This SFCL is designed for the HVDC system. Uniform \\
\hline Renewable energy sources & current and voltage sharing among the SFCL modules can be observed \\
\hline Resistive-type superconducting & through contact resistance tests, dc flow-through tests, and ac flow-through \\
\hline fault current limiter (SFCL) & tests. Results of tests show that each limiting module has good uniformity in \\
\hline $\begin{array}{l}\text { Short circuit current } \\
\text { Uniformity }\end{array}$ & $\begin{array}{l}\text { higher current system. The proposed concept can be implemented using } \\
\text { renewable energy sources. The results are presented by using }\end{array}$ \\
\hline & Matlab/simulink platform. \\
\hline
\end{tabular}

\section{Copyright $@ 2017$ Institute of Advanced Engineering and Science.
All rights reserved. \\ Copyright (c) 2017 Institute of Advanced Engineering and Science.
All rights reserved.}

\section{Corresponding Author:}

\section{S.Sanjeeva Rayudu}

Department of Electrical \& Electronics Engineering,

Annamacharya Institute of Technology \& Science, India.

\section{INTRODUCTION}

DC power systems are widely used because of its flexible, low maintenance cost and fast transient capability. However, for bulk power transmission over long distances high voltage dc (HVDC) transmission lines are preferred. Due to the high power capacity, reliable and safety performance are critical for such dc systems. Size of conductor in dc transmission can be reduced as there is no skin effect. However, for largepower transmission over long distances, HVDC turns out to be economical. In order to achieve safety performance, fault protection and tolerance are usually required. In dc grids, the fault current has no zero crossing point as the ac current does. So it is difficult to open the over current fault transmission line. Superconducting fault current limiter (SFCL) is one of the most ideal current limiting devices to protect the system and electrical equipments. It can limit the fault current effectively in power systems and prevent damage to the circuit components within several milliseconds. Over the years, HVDC transmission has been constantly developing in China. Multiple HVDC transmission lines have been built in China [1], [2]. With the increase of power system capacity and the development of transmission technique, the short circuit current will reach the peak current which ranges between kiloampere and tens of kiloamperes within several milliseconds.

At present, using circuit breakers to cut off the fault current is widely applied in the dc system to ensure the whole system safety. However, the rated ultimate breaking capacity is limited, which will not meet the requirement of constant increase in short circuit current level. Recently, the dc breaker developed by $\mathrm{ABB}$ can cut off a $16 \mathrm{kA}$ fault current within $2 \mathrm{~ms}$ while its rated voltage is $320 \mathrm{kV}$ [3], and Alstom has 
developed a dc breaker that can cut off a $7.5 \mathrm{kA}$ fault current within $1.6 \mathrm{~ms}$ while the rated voltage is $120 \mathrm{kV}$ [4]. The SFCL could bring a solution to the main bottleneck of the dc networks and the interruption of the fault current.

Most of the SFCL prototypes up to now have been designed for ac systems [5]-[8]. This paper introduces a dc SFCL prototype. This resistive type SFCL prototype has been designed and constructed by Shanghai Jiao Tong University. The prototype will be applied in an isolated dc network as an Ingrid demonstration to prove the current limiting ability of SFCL in dc systems. In this paper, renewable energy source can be applied at the input side. HVDC can connect remote sources of electrical power often emissions-free renewable energy sources like hydro or wind generation to load centres where it is needed, hundreds or even thousands of kilometers away.

For a real gird demonstration, the utilities require the SFCL to provide good current limiting performance. So the HTS tapes are chosen based on their characteristics. Then simulations are carried out to optimize the limiting effect and determine the SFCL parameters. A series of experiments are conducted to test the characteristics of a single module and the whole SFCL prototype before demonstration.

\section{HIGH TEMPERATURE SUPERCONDUCTOR TAPES TEST}

A high power dc short circuit test platform is built to verify the limiting effect of the second generation $(2 \mathrm{G})$ high temperature superconductor (HTS) tapes in dc power systems. The platform is composed of a step-down transformer, an uncontrolled rectifier bridge and a short-circuit control circuit, as shown in Figure 1. The system voltage is provided by an isolated transformer which has variable secondary 20/40/100 VAC.

The low voltage level is good for the safety of the test system, so the experiments are conducted when the voltage is $20 \mathrm{VAC}$ and $40 \mathrm{VAC}$. So the dc voltage behind the rectifier bridge is about $28 \mathrm{~V}$ and 56 $\mathrm{V}$. Without the superconducting limiting module, the normal current and the short circuit current are, respectively $6.7 \mathrm{~A}$ and $1750 \mathrm{~A}$ when the transformer provides $20 \mathrm{VAC}$ signals; and they are, respectively 13.3 A and $3150 \mathrm{~A}$ when the transformer provides $40 \mathrm{VAC}$ signals. Because of the capacitor and resistors of release circuit, the fault current is not linear.

Superconducting limiting module of two types of HTS tapes, respectively produced by the Physics Department of Shanghai Jiao Tong University (SJTU) and American Superconductor Corporation (AMSC), are applied to the dc system to prove the current limiting ability of superconducting materials.

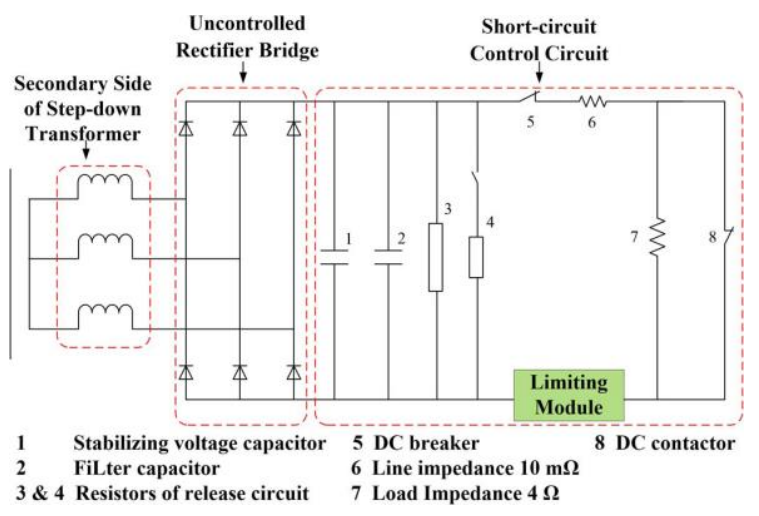

Figure 1. Overall Test Platform

\begin{tabular}{ccccc}
\multicolumn{5}{c}{ Table 1. Parameters of HTS Tapes } \\
\hline \hline Quantity & $\begin{array}{c}\text { Width } \\
(\mathrm{mm})\end{array}$ & $\begin{array}{c}\text { Thickness } \\
\text { of Cooper } \\
\text { Layer }(\mathrm{mm})\end{array}$ & $\begin{array}{c}\text { Thickness } \\
\text { of Whole } \\
\text { Layer }(\mathrm{mm})\end{array}$ & $\begin{array}{c}\text { Resistance at } \\
\text { Room Temperature } \\
(\mathrm{m} \Omega / \mathrm{m})\end{array}$ \\
\hline SJTU Tape & 10 & 0.060 & 0.163 & 31.6 \\
AMSC Tape & 12 & 0.075 & 0.202 & 21.1 \\
\hline \hline
\end{tabular}

The critical currents of both two types of HTS tapes are 250 A. The length of HTS tapes consisted in the limiting module are 6 meters. The parameters of two types of HTS tapes are shown in Table 1. Short 
circuit experiments with the limiting module are conducted when the transformer supplies 20 VAC and 40 VAC. The circuit current is obtained by testing the voltage of the line resistor. The duration of short circuit is $100 \mathrm{~ms}$. Short circuit current and the resistance of the superconducting limiting module in 20 VAC and 40 VAC systems are shown in Figure 2. Some characteristics of limiting effect in the dc system are got from the experiments, as shown in Table II. From Figure 2 and Table II, we observe that superconducting materials also have the ability of limiting current in dc systems. The SJTU tape is narrower and thinner than that produced by AMSC, so it has larger room temperature resistance and the fault current in the circuit with SJTU tapes is smaller. However, the AMSC tape has better heat dissipation because of its thicker stabilized copper layer. Besides, SJTU tape has a bigger $\mathrm{n}$ value, leading to a faster quench response. It is also observed that both SJTU and AMSC tapes could limit the fault current before the current reaches the peak value.

Table 2. Characteristic Parameters of Limiting Effect

\begin{tabular}{lllll}
\hline \hline Quantity & $\begin{array}{c}\text { Peak Value of } \\
\text { Short Circuit } \\
\text { Current (A) }\end{array}$ & $\begin{array}{c}\text { Time of } \\
\text { Peak Value } \\
(\mathrm{ms})\end{array}$ & $\begin{array}{c}\text { Maximum } \\
\text { Voltage on } \\
\text { SFCL }(\mathrm{V})\end{array}$ & $\begin{array}{c}\text { Temperature } \\
\text { of HTS } \\
\text { Tapes }(\mathrm{K})\end{array}$ \\
\hline $20 \mathrm{~V}$ & 1750 & 4 & -- & - \\
$20 \mathrm{~V} /$ SJTU & 852 & 2.5 & 18.5 & 95.9 \\
$20 \mathrm{~V} /$ AMSC & 1080 & 3 & 13.9 & 92.87 \\
$40 \mathrm{~V}$ & 3150 & 4 & -- & -- \\
$40 \mathrm{~V} /$ SJTU & 1370 & 2 & 50.2 & 128.5 \\
$40 \mathrm{~V} /$ AMSC & 2000 & 3 & 42 & 120.8 \\
\hline \hline
\end{tabular}

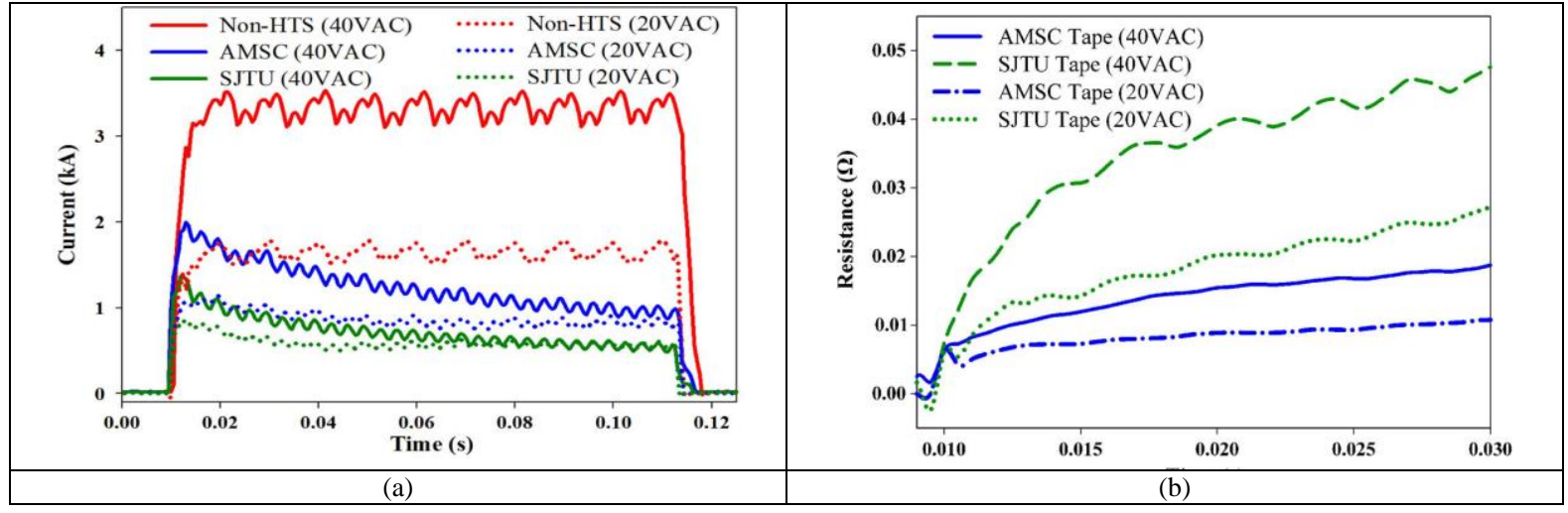

Figure 2. (a) Short Circuit Current. (b) Resistance of the Super-conducting Limiting Module

\section{DESIGN OF SFCL MODULE}

Based on the HTS tapes tests in Section II, super-conducting materials are proved to have the limiting ability in dc network. This part will introduce a dc SFCL prototype which will be applied into a real isolated dc network. The critical current should not only be greater than the normal current, but also have a certain safety margin. So according the real isolated DC system, the critical current of the SFCL module is set as $5 \mathrm{kA}$. Considering the voltage tolerance of YBCO coated conductors [9], the length of the HTS tapes in series is set as $66 \mathrm{~m}$.

Double-insert YBCO tapes produced by AMSC are used in the SFCL prototype to save the module space. The critical current of the double-insert YBCO tapes is $500 \mathrm{~A}$, so 10 modules are needed to meet the requirement of $5 \mathrm{kA}$ critical current. The structure of a single current limiting module [10] is shown in Figure 3. Each module contains 116 pieces of $0.57 \mathrm{~m}$ long YBCO tapes which are connected in a combination of series and parallel. Every 58 YBCO tapes are connected in series to form one current path at one side of G10 former and two paths are connected in parallel. Every two tapes are soldered together at the ends with a short YBCO tape and are fixed on the G10 former with copper terminals. There are totally $33 \mathrm{~m}$ long YBCO tapes in series and two current paths in one limiting module. The SFCL module needs $66 \mathrm{~m}$ long YBCO tapes in series and 10 paralleled branches. So the whole SFCL module is designed as shown in Figure 4(a) and the real SFCL module is shown in Figure 4(b). It consists of two parts in series and each part has 5 G10 formers in parallel which have 10 paralleled tapes. The performances of a single module and the laboratory test of the whole SFCL prototype have been fully conducted and the results will be presented in the paper. And in-gird test will start in October 2013. 


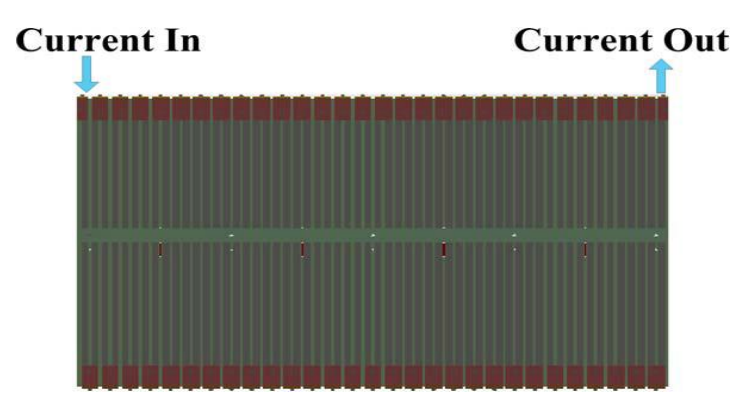

Figure 3. Structure of a Single Current Limiting Module

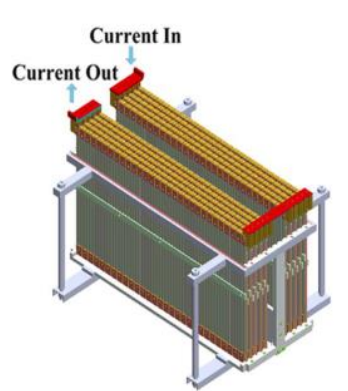

(a)

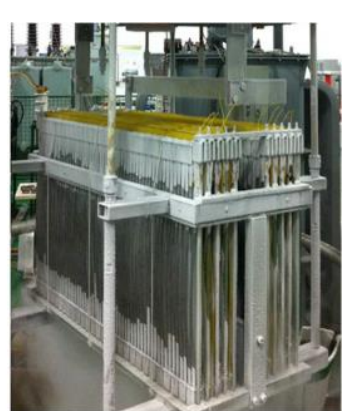

(b)

Figure 4. (a) Structure of the Whole SFCL Module. (b) Real SFCL Module.

\section{MODULE TESTS}

\subsection{Contact Resistance Test For A Single Module}

There are 10 limiting modules in parallel in this SFCL. If the current is not equally distributed and one module has higher current than others, the current path quenches first and others follow even without fault. Unbalanced current distribution may lead to a disaster during the normal operation. So the contact resistance of current paths has to be measured to ensure the uniformity of the current of each limiting module. Contact resistances of 20 current paths are shown in Table 3. Table 3 shows that contact resistances of most current paths are between $0.10 \mathrm{~m} \Omega$ to $0.12 \mathrm{~m} \Omega$. Some of the contact resistances are a little larger because of the soldering technique. The maximum and minimum contact resistances are, respectively 0.163 $\mathrm{m} \Omega$ and $0.101 \mathrm{~m} \Omega$.

To solve the uniformity problem, the data of contact resistances has been optimized. 20 current paths are divided into pairs. Each pair of current paths has similar value of contact resistance and is treated as the two sides of a limiting module. For example, path 10 and path 20 sharing the biggest value are chosen to form the two sides of a limiting module with the biggest contact resistance. Then the ten limiting modules are divided into two groups. Five of them having a larger contact resistance are in a group and labeled as part I. And then the others with a smaller contact resistance are in a group and labeled as part II. In this way, the current uniformity of each limiting module is improved. The maximum and minimum contact resistances of a single limiting module are about $0.081 \mathrm{~m} \Omega$ and $0.052 \mathrm{~m} \Omega$, respectively. To analyze the distribution of dc current, some calculations are performed on the basis of such module contact resistances. The modules with the biggest and smallest contact resistances account for about $16.05 \%$ and $22.03 \%$ of the total current, respectively. The percentage difference is $5.98 \%$.

Table 3. Contact Resistance of 20 Current Paths

\begin{tabular}{llllll}
\hline \hline No. & $\begin{array}{c}\text { Contact } \\
\text { Resistance } \\
(\mathrm{m} \Omega)\end{array}$ & No. & $\begin{array}{c}\text { Contact } \\
\text { Resistance } \\
(\mathrm{m} \Omega)\end{array}$ & No. & $\begin{array}{c}\text { Contact } \\
\text { Resistance } \\
(\mathrm{m} \Omega)\end{array}$ \\
\hline 1 & 0.140 & 8 & 0.101 & 15 & 0.116 \\
2 & 0.133 & 9 & 0.127 & 16 & 0.108 \\
3 & 0.108 & 10 & 0.162 & 17 & 0.116 \\
4 & 0.113 & 11 & 0.122 & 18 & 0.115 \\
5 & 0.109 & 12 & 0.114 & 19 & 0.124 \\
6 & 0.117 & 13 & 0.117 & 20 & 0.163 \\
7 & 0.155 & 14 & 0.112 & -- & -- \\
\hline
\end{tabular}




\subsection{Flow-Through Test}

The SFCL module is assembled after the 10 limiting modules have been optimized and grouped. In order to test the current uniformity of each limiting module in liquid nitrogen (LN2), the dc flow-through test is carried out for the whole SFCL module. Different dc currents are applied to the whole SFCL module in LN2. We use multi-channel data acquisition system to measure the current of every limiting module. The current is shown in Figure 5.

Figure 5 shows that the currents of most modules are similar. The maximum and the minimum values of the currents are shown in Table 4.

From the Table 4, it is observed that the percentage difference is about $6.1 \%$. This percentage difference of experiments is a little bigger than that in part A by calculation because contact resistance also contains the joint resistance between limiting modules and the copper current bus. This contact resistance brings more unbalanced current.

According to the system current and the percentage difference in Table IV, the difference between the maximum and minimum currents of limiting modules is about $152.5 \mathrm{~A}$. The maximum current of a single limiting module with two current paths is about $595 \mathrm{~A}$, which is safe to YBCO tapes. And the difference of currents is acceptable for the whole SFCL.

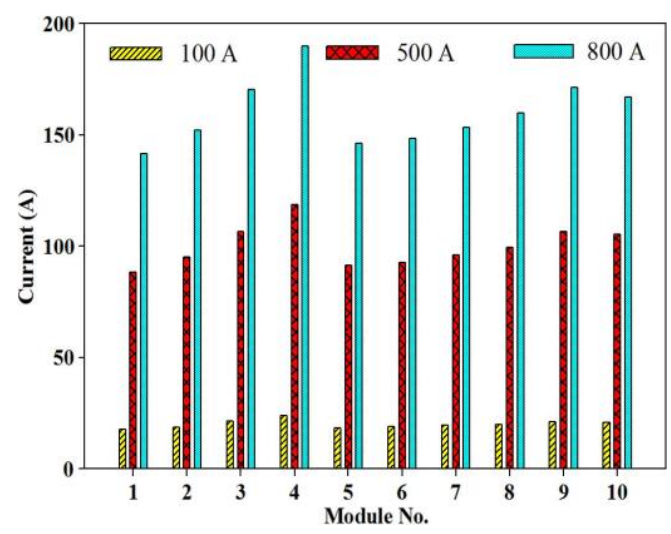

Figure 5. Distribution of the DC Current

Table 4. Maximum and Minimum Values of the Currents

\begin{tabular}{lllll}
\hline \hline $\begin{array}{c}\text { DC } \\
\text { Current (A) }\end{array}$ & $\begin{array}{l}\text { Maximum } \\
\text { Current (A) }\end{array}$ & $\begin{array}{c}\text { Minimum } \\
\text { Current (A) }\end{array}$ & $\begin{array}{c}\text { Difference of } \\
\text { Current (A) }\end{array}$ & $\begin{array}{c}\text { Percentage } \\
\text { Difference (\%) }\end{array}$ \\
\hline 100 & 23.92 & 17.59 & 6.33 & 6.33 \\
500 & 118.56 & 88.20 & 30.36 & 6.07 \\
800 & 189.89 & 141.49 & 48.40 & 6.05 \\
\hline \hline
\end{tabular}

\subsection{AC Flow-Through Test}

The dc current source can provide a maximum current of 875 A. So ac flow-through experiment is conducted to test the uniformity of every limiting module in a higher current system. And the test results will be useful for the power capacity ac system in the future. The system voltage is provided by a voltage regulator which can vary up to $660 \mathrm{~V}$. The voltage regulator is connected with a $220 \mathrm{~V} / 5 \mathrm{~V}$ step-down transfor-mer. The test circuit is shown in Figure. 6(a) and the dc SFCL prototype with a shunt resistor is shown in Figure. 6(b).

The SFCL prototype is connected in parallel with a shunt resistor. The line resistance is in series with the transformer and SFCL. A series of tests have been performed at different voltage levels. Current flowing through the SFCL is measured by ac current sensor and the voltage of every limiting module is tested by a multi-channel oscilloscope YOKOGAWA DL850. The test data is shown in Table V.

Table 5 shows that the module 1-5 have larger voltages than module $6-10$ because the former has bigger contact resistances than the latter. However, the voltages of module 1-5 are very similar, so is the module 6-10. The results show that each limiting module has good uniformity in a higher current system. It can meet the requirements of the real isolated dc system. 


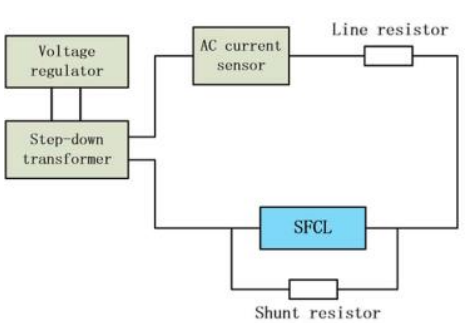

(a)

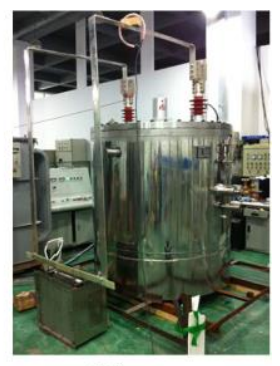

(b)

Figure 6. (a) AC Flow-Through Test Platform. (b) DC SFCL Prototype

Table 5. AC Flow-Through Test

\begin{tabular}{|c|c|c|c|}
\hline & 630 Arms & 1296 Arms & 1768 Arms \\
\hline 1 & $0.365 \mathrm{~V}$ & $0.769 \mathrm{~V}$ & $1.070 \mathrm{~V}$ \\
\hline 2 & $0.368 \mathrm{~V}$ & $0.776 \mathrm{~V}$ & $1.080 \mathrm{~V}$ \\
\hline 3 & $0.374 \mathrm{~V}$ & $0.789 \mathrm{~V}$ & $1.090 \mathrm{~V}$ \\
\hline 4 & $0.383 \mathrm{~V}$ & $0.809 \mathrm{~V}$ & $1.120 \mathrm{~V}$ \\
\hline 5 & $0.381 \mathrm{~V}$ & $0.802 \mathrm{~V}$ & $1.110 \mathrm{~V}$ \\
\hline 6 & $0.291 \mathrm{~V}$ & $0.620 \mathrm{~V}$ & $0.872 \mathrm{~V}$ \\
\hline 7 & $0.298 \mathrm{~V}$ & $0.633 \mathrm{~V}$ & $0.889 \mathrm{~V}$ \\
\hline 8 & $0.298 \mathrm{~V}$ & $0.634 \mathrm{~V}$ & $0.891 \mathrm{~V}$ \\
\hline 9 & $0.293 \mathrm{~V}$ & $0.624 \mathrm{~V}$ & $0.878 \mathrm{~V}$ \\
\hline 10 & $0.295 \mathrm{~V}$ & $0.628 \mathrm{~V}$ & $0.884 \mathrm{~V}$ \\
\hline
\end{tabular}

\begin{tabular}{|lll|}
\hline \multicolumn{3}{|c|}{ Table 6. Limiting Effects of Different } \\
\hline \hline $\begin{array}{c}\text { Shunt } \\
\text { Resistor }(\Omega)\end{array}$ & $\begin{array}{c}\text { Short Circuit } \\
\text { Current with SFCL } \\
\text { (per unit value) }\end{array}$ & $\begin{array}{c}\text { Fault Current } \\
\text { Reduction } \\
\text { Percentage (\%) }\end{array}$ \\
\hline 0.4 & $\mathbf{0 . 5 3 8 8}$ & 46.12 \\
0.6 & $\mathbf{0 . 5 0 7 6}$ & 49.24 \\
0.8 & $\mathbf{0 . 4 9 0 0}$ & 51.00 \\
\hline \hline
\end{tabular}

\section{MODELING AND SIMULATION}

Before the Ingrid test, simulations are carried out to research the current limiting effect. The dc network is built in Matlab/simulink based on the real parameters of the isolated system. The SFCL model [11] is used in the system to simulate its impact on the dc network. The simulation model in Matlab/simulink is shown in Figure 7. A series of simulations are carried out to determine the value of shunt resistor. The room temperature resistance of SFCL is about $0.452 \Omega$. So the value of shunt resistor should be around 0.5 $\Omega$. The current limiting effects of different shunt resistors are shown in Table VI. Considering the limiting effect and the cooperation with other electrical equipments, the shunt resistor in parallel with the superconductor is set as $0.6 \Omega$ to adjust the limited current and to avoid the over-voltages. The dc system is stable at $\mathrm{t}=0.7 \mathrm{~s}$. Simulations are carried out with the short-circuit fault happened at $\mathrm{t}=0.8 \mathrm{~s}(\mathrm{t}=0 \mathrm{~s}$ at the beginning of the simulation), and the fault will be clear at $t=1.0 \mathrm{~s}$. The total simulation time is $200 \mathrm{~ms}$. Short circuit currents with and without SFCL are shown in Figure 8. The short circuit currents in Figure 8(a) are damped oscillation curves because of the large inductance and large capacitor behind the rectifier bridge used to stabilize the dc current and voltage. From Figure 8(a), it is observed that the short-circuit current is significantly limited by SFCL. The response time of SFCL is about $1.5 \mathrm{~ms}$, as shown in Figure $8(\mathrm{~b})$. The peak value of fault current is limited to about $50 \%$ of the fault current without SFCL within 2 ms. The simulation results show SFCL has the current limiting ability in the real isolated de network and will provide the important reference for the field test in Ingrid demonstration.

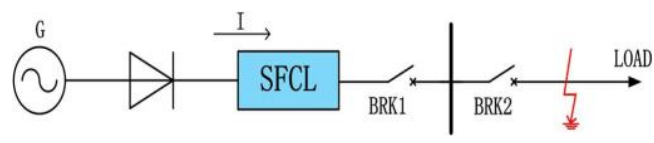




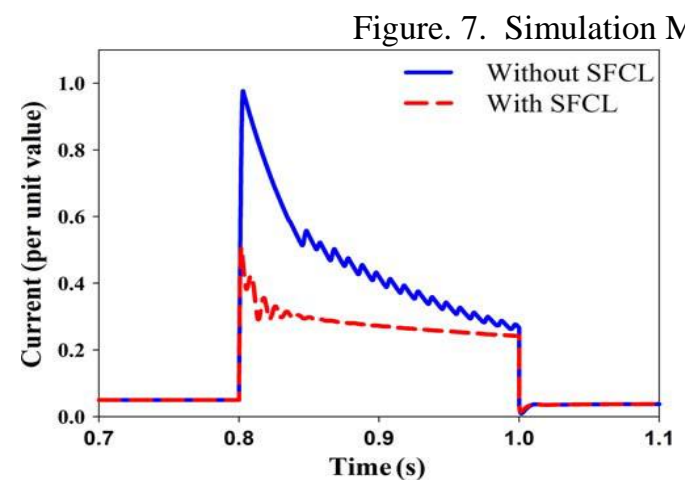

(a)

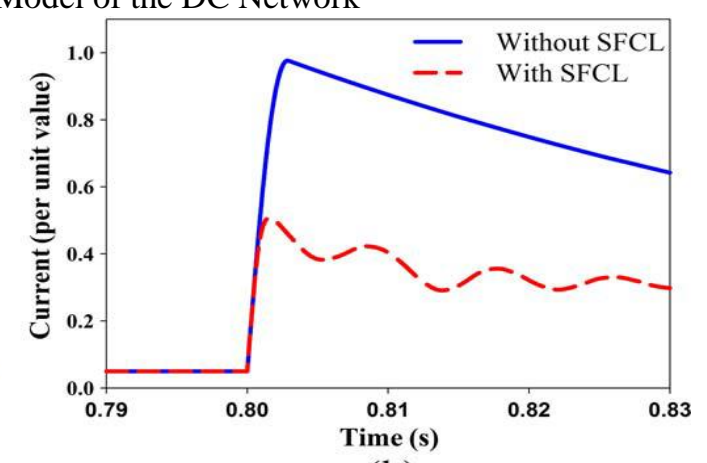

(b)

Figure 8. (a) Short Circuit Current Curves With and Without SFCL. (b) Rising Edge of Short Circuit Current Curves With and Without SFCL

\section{CONCLUSION}

The design and analysis of a dc SFCL with Renewable energy source has been introduced in this paper. A series of tests of HTS tapes produced by SJTU and AMSC are carried out to test the tape characteristics and to prove the current limiting ability of superconducting materials. SFCL modules are assembled together through optimizing the contact resistance data of 10 limiting modules. DC and AC flowthrough tests are carried out to measure the uniformity of each limiting module. The test results show that the module uniformity can meet the requirements of the real isolated dc network. Based on the test data, simulations are performed to research the impact of SFCL on a real dc system and determine the SFCL parameters suitable for the network. Simulation results indicate that the dc SFCL needs $66 \mathrm{~m} \mathrm{YBCO} \mathrm{tapes} \mathrm{in}$ series and 10 limiting modules in parallel. The SFCL with a $0.6 \Omega$ shunt resistor is able to reduce the fault current to $50.76 \%$ of the original value.

\section{REFERENCES}

[1] Y. Huang and Z. Xu, "Study on the pure dc transmission scheme for China's future power transmission form the west to east," in Proc. IEEE Power Eng. Soc. Gen. Meet., 2004, pp. 1459- 1463.

[2] H. Huang, Z. Xu, W. Wang, and C. Wang, "Transient stability analysis of shanghai power grid with multiple HVDC links," in Proc. Int. POWERCON Syst. Technol., pp. 1-6.

[3] L. Xiao, S. Dai, L. Lin, Z. Zhang, and J. Zhang, "HTS power technology for future DC power grid," IEEE Trans. Appl. Supercond., vol. 23, no. 3, p. 5401506, Jun. 2013.

[4] G. F. Tang, "Multiple-terminal DC power transmission and DC power grid technology," presented at the Fragrant Hill Sci. Meeting, Beijing, China, Sep. 27-29, 2012.

[5] L. Ye and L. Lin, "Study of superconducting fault current limiters for system integration of wind farms," IEEE Trans. Appl. Supercond., vol. 20, no. 3, pp. 1233-1237, Jun. 2010.

[6] O. B. Hyun, H. R. Kim, J. Sim, Y. H. Chung, K. B. Park, B. W. Lee, and I. S. Oh, "6.6 kV resistive superconducting fault current limiter based on YBCO films," IEEE Trans. Appl. Supercond., vol. 15, no. 2, pp. 2027-2030, Jun. 2005.

[7] L. Martini, M. Bocchi, M. Ascade, A. Valzasina, V. Rossi, C. Ravetta, and G. Angel, "Live-grid installation and field testing of the first Italian superconducting fault current limiter," IEEE Trans. Appl. Supercond., vol. 23, no. 3, p. 5602504, Jun. 2013.

[8] H. Shin, S. Cho, J. Huh, J. Kim, and D. Kweon, "Application on of SFCL in automatic power changeover switch system of electric railways," IEEE Trans. Appl. Supercond., vol. 22, no. 3, p. 5600704, Jun. 2012.

[9] M. Noe, A. Hobl, P. Tixador, L. Martini, and B. Dutoit, "Conceptual design of a $24 \mathrm{kV}, 1 \mathrm{kA}$ resistive superconducting fault current limiter," IEEE Trans. Appl. Supercond., vol. 22, no. 3, p. 5600304, Jun. 2012.

[10] Z. Hong, J. Sheng, J. Zhang, B. Lin, L. Ying, Y. Li, and Z. Jin, "The development and performance test of a $10 \mathrm{kV}$ resistive type superconducting fault current limiter," IEEE Trans. Appl. Supercond., vol. 22, no. 3, p. 5600504, Jun. 2012.

[11] Y. Chen, S. Li, J. Sheng, Z. Jin, Z. Hong, and J. Gu, "Experimental and numerical study of co-ordination of resistive-type superconductor fault current limiter and relay protection," J. Supercond. Novel Magn., vol. 26, no. 11, pp. 3225-3230, Nov. 2013. 